\title{
Electrospun polystyrene fiber-templating ultrafine gold hollow fiber production
}

\author{
Shinji Sakai • Shogo Kawa • Koichi Sawada • \\ Masahito Taya \\ Published online: 9 March 2013 \\ (C) The Author(s) 2013. This article is published with open access at SpringerLink.com
}

\begin{abstract}
Ultrafine gold hollow fibers of about $1.5 \mu \mathrm{m}$ in outer diameter and $1 \mu \mathrm{m}$ in hollow core diameter, i.e., about $250 \mathrm{~nm}$ of gold sheath thickness, were produced in combination with electrospinning technique, photoreduction, electroless plating, and heat treatment for removing template polymer fibers. The gold sheath was fabricated through electroless plating on electrospun polystyrene fibers of about $1 \mu \mathrm{m}$ diameter using the gold nanoparticles formed in situ in the fibers by irradiation of ultraviolet light as seeds of the gold sheath formation. Then, a hollow core structure was developed by treating the resultant fibers at 180,350 , or $800^{\circ} \mathrm{C}$. Scanning electron microscopy imaging showed the formation of a hollow core structure in the fibers by the treatment at $180^{\circ} \mathrm{C}$ as well as those treated at 350 and $500{ }^{\circ} \mathrm{C}$. These results demonstrate the possibility of fabrication of ultrafine gold hollow fibers using electrospun polystyrene fibers as a template of the hollow core structure.
\end{abstract}

Keywords Electrospinning $\cdot$ Electroless plating $\cdot$ Gold hollow fiber · Photoreduction · Polystyrene

\section{Introduction}

Electrospinning first patented in the USA in 1902 [1] has received a dramatic revival of interest in the last decade as a technology by which ultrafine fibers with diameters ranging from several microns to down to $100 \mathrm{~nm}$ or less can be prepared from a wide variety of materials [2]. The small diameter of individual fibers induces remarkable characteristics of the resultant nonwoven fabrics due to a very large surface areato-volume ratio, high porosity, and very small pore size [3]. A

S. Sakai $(\varangle) \cdot$ S. Kawa $\cdot$ K. Sawada $\cdot$ M. Taya

Division of Chemical Engineering, Department of Materials

Science and Engineering, Graduate School of Engineering

Science, Osaka University, 1-3 Machikaneyama-cho,

Toyonaka, Osaka 560-8531, Japan

e-mail: sakai@cheng.es.osaka-u.ac.jp variety of electrospun fibers have been made for applications in energy storage, healthcare, biotechnology, and environmental engineering [3]. The aim of the present study is to fabricate ultrafine gold hollow fibers using the electrospun fibers as a template of the hollow core. Fabrications of nanotubes and ultrafine hollow fibers have attracted much attention for their structural particularity because such structural modifications could further enhance material properties for the aforementioned applications [4]. In the present work, we attempted to prepare ultrafine gold hollow fibers by combining electrospinning technique with subsequent processes of electroless plating and removal of the original polymer fibers. Electroless plating is a method of depositing metal onto insulating substrates without having to use electricity. There are literatures for successful coating of gold onto electrospun polyacrylonitrile (PAN) fibers using the electroless plating process $[1,5]$. In the preceding literatures, no attempts have been performed for developing a hollow core structure in the fibers. In this study, we used electrospun polystyrene (PS) fibers for the electroless plating of gold because polystyrene decomposes even around $200{ }^{\circ} \mathrm{C}$ in air [6]. The ultrafine gold hollow fibers were prepared through following four steps: (1) The PS fibers containing $\mathrm{HAuCl}_{4}$ were electrospun, (2) gold ions in the PS fibers were reduced by ultraviolet (UV) irradiation, (3) a gold sheath was electrolessly deposited on the PS fibers, and (4) a hollow core structure was developed by decomposing the PS fibers by heat treatment (Fig. 1).

\section{Experimental}

Electrospinning

Polystyrene (MW 280,000, Sigma, MO, USA) was dissolved in dimethylformamide (DMF) at $15 \%(w / w)$, followed by addition of $3 \%(w / w) \mathrm{HAuCl}_{4} 4 \mathrm{H}_{2} \mathrm{O}$ (Kanto Chemical, Tokyo, Japan) and stirring to a homogeneous yellowish color solution for about $10 \mathrm{~min}$. The resultant solution was loaded into a plastic syringe 


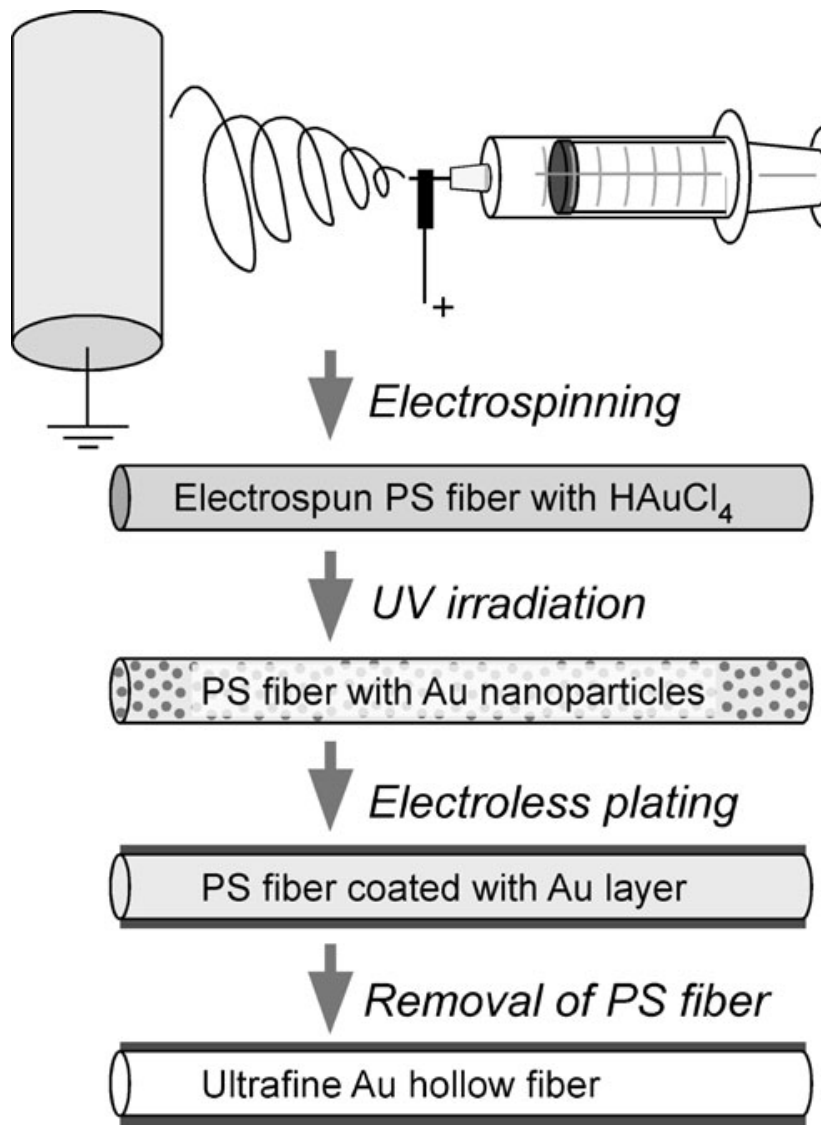

Fig. 1 Scheme of ultrafine gold hollow fiber preparation from electrospun PS fibers enclosing $\mathrm{HAuCl}_{4}$

equipped with a 20-gauge stainless steel needle, and then extruded at $2 \mathrm{~mL} / \mathrm{h}$ under being applied at $+20 \mathrm{kV}$ using a highvoltage DC generator. The needle connected to the DC supply was located $12 \mathrm{~cm}$ from an earthed counter electrode.

\section{Electroless plating}

The resultant PS fibrous mat containing $\mathrm{HAuCl}_{4}$ was dried in vacuo. Then, the fibrous mat was irradiated UV for 1 day by putting the specimen $60 \mathrm{~cm}$ from a UV lamp $\left(51 \mathrm{~mW} / \mathrm{m}^{2}\right)$. Through this process, the gold salt embedded in the PS fibers was reduced to form gold nanoparticles as catalytic seed metal of the subsequent gold coating. The PS fibers containing gold nanoparticles $(4 \mathrm{mg})$ were put into a membrane filtration folder of $25 \mathrm{~mm}$ in diameter. Then, $600 \mathrm{~mL}$ of $0.01 \%(w / w)$ $\mathrm{HAuCl}_{4} 4 \mathrm{H}_{2} \mathrm{O}$ solution cooled in an ice bath was circulated at $12 \mathrm{~mL} / \mathrm{min}$ through the PS fibrous mat until the electroless plating solution became colorless for $2 \mathrm{~h}$.

\section{Removal of PS fibers}

The fibrous specimen treated with the electroless plating was rinsed with distilled water and then dried in vacuo.
Subsequently, the dried specimen was kept in an oven at $180{ }^{\circ} \mathrm{C}$ for 2 or 3 days, or at 350 or $500^{\circ} \mathrm{C}$ for $2 \mathrm{~h}$.

Scanning and transmission electron microscopies observations

Morphologies of the electrospun fibers before and after the treatment of the electroless plating were observed using a scanning electron microscope (SEM, Model S-2250 N, Hitachi Ltd., Tokyo, Japan) after drying in vacuo. Formation of gold nanoparticles in the fibers after the UV irradiation was observed using a transmission electron microscope (TEM, Model H-800, Hitachi Ltd., Tokyo, Japan) operating at $100 \mathrm{kV}$ and magnification value of $100 \mathrm{k}$. Samples were dispersed in water, and a drop of the resultant suspension was poured on a carbon coatedcopper grid.
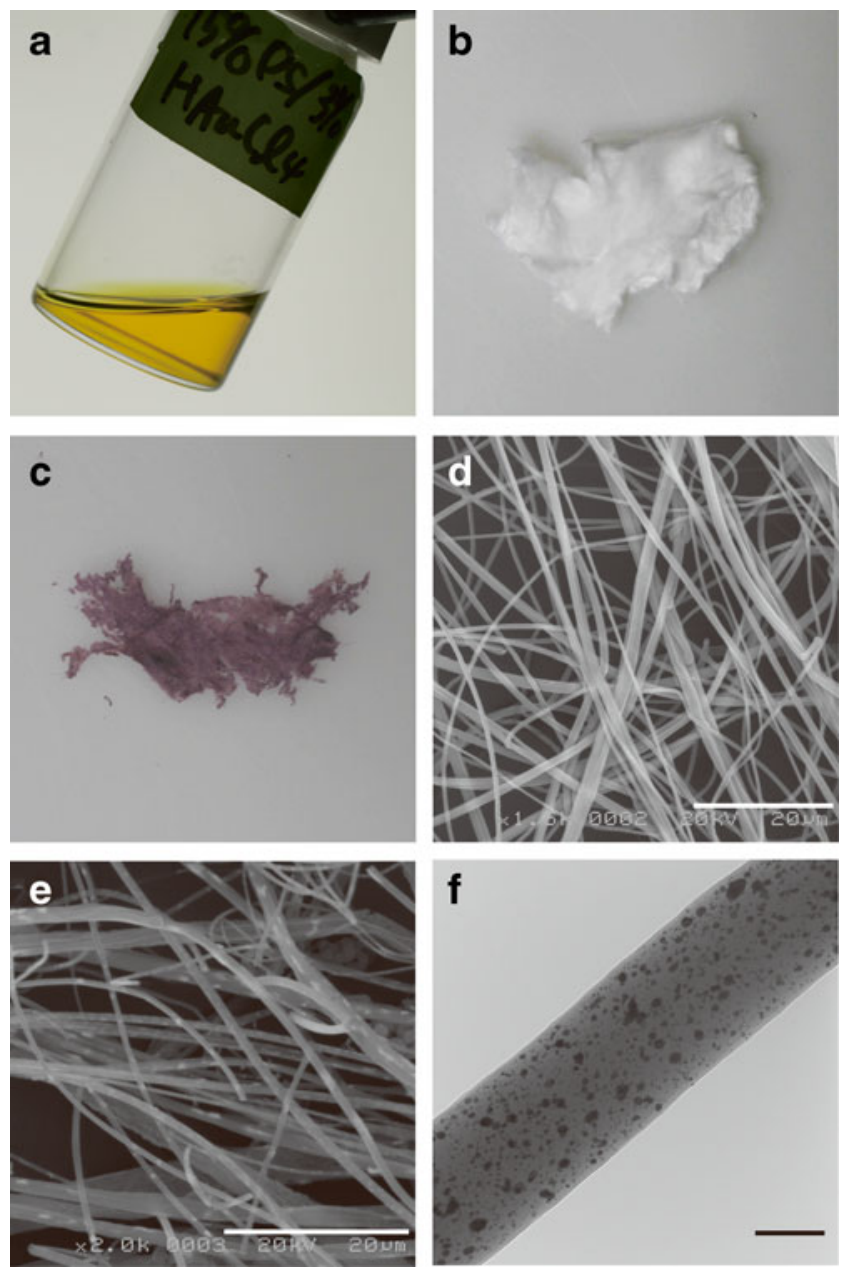

Fig. 2 Photographs of a homogeneous solution containing PS and $\mathrm{HAuCl}_{4} 4 \mathrm{H}_{2} \mathrm{O}$ at 15 and $3 \%(w / w)$ before electrospinning, and fibrous mat of electrospun PS fibers $\mathbf{b}$ before and $\mathbf{c}$ after UV irradiation. SEM images of PS fibers $\mathbf{d}$ before and $\mathbf{e}$ after UV irradiation. $\mathbf{f}$ TEM image of gold nanoparticles (black dots) formed in PS fibers through UV irradiation. Bars in $\mathbf{d}$ and e, $20 \mu \mathrm{m}$; Bar in f, $200 \mathrm{~nm}$ 
Fig. 3 SEM images of PS fibers after electroless plating of fibers a with and $\mathbf{b}$ without containing gold nanoparticles, calcined at $\mathbf{c} 350{ }^{\circ} \mathrm{C}$ and $\mathbf{d}$ $500{ }^{\circ} \mathrm{C}$ for $2 \mathrm{~h}$, and at $180{ }^{\circ} \mathrm{C}$ for $\mathbf{e} 2$ days and $\mathbf{f} 3$ days. The arrows in $\mathbf{e}$ and $\mathbf{f}$ indicate remaining PS layer. Bars in a and $\mathbf{b}, 20 \mu \mathrm{m} ;$ Bar in c, $3 \mu \mathrm{m}$; bars in $\mathbf{d}$ and $\mathbf{e}, 2 \mu \mathrm{m}$; and $B a r$ in $\mathbf{f}, 1.5 \mu \mathrm{m}$
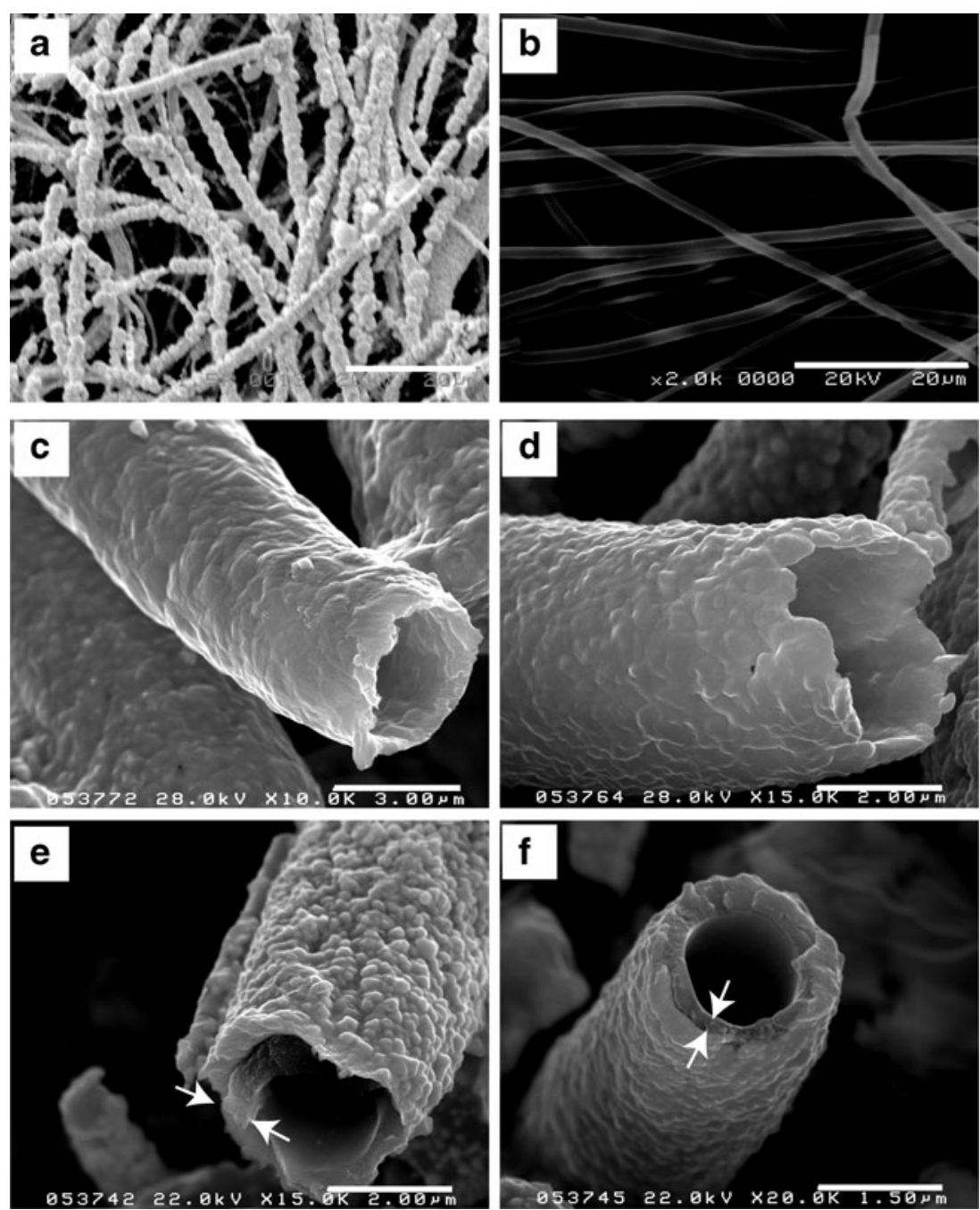

Thermal measurement

Weight change of the dried specimen with a gold sheath was determined using a thermal analyzer (STA6000, PerkinElmer, Inc, MA, USA) in the temperature range from 80 to $600{ }^{\circ} \mathrm{C}$ in air. At 180,350 , and $500{ }^{\circ} \mathrm{C}$, these temperatures were held for 1 or $2 \mathrm{~h}$. A heating rate except for the temperature holding periods was $10{ }^{\circ} \mathrm{C} / \mathrm{min}$. About $10 \mathrm{mg}$ of specimen was used for the measurement.

\section{Results and discussion}

PS is one of the polymers which has been electrospun [7, 8]. In preliminary experiment, we attempted to dissolve $\mathrm{HAuCl}_{4} 4 \mathrm{H}_{2} \mathrm{O}$ at $15 \%(w / w)$ with $15 \%(w / w)$ PS in DMF. Under this condition, homogeneous solution was not obtained. Thus, we decreased the content of $\mathrm{HAuCl}_{4} 4 \mathrm{H}_{2} \mathrm{O}$ to $3 \%(w / w)$, and could obtain homogeneous yellowish solution (Fig. 2a). Electrospun fibers containing $\mathrm{HAuCl}_{4}$ were prepared from the homogeneous solution. The diameter of as spun PS fibers containing $\mathrm{HAuCl}_{4}$ was $0.89 \pm$ $0.37 \mu \mathrm{m}$. The contents of PS and $\mathrm{HAuCl}_{4}$ in the resultant fibers were $83 \%(w / w)$ and $17 \%(w / w)$, respectively, after removing DMF.

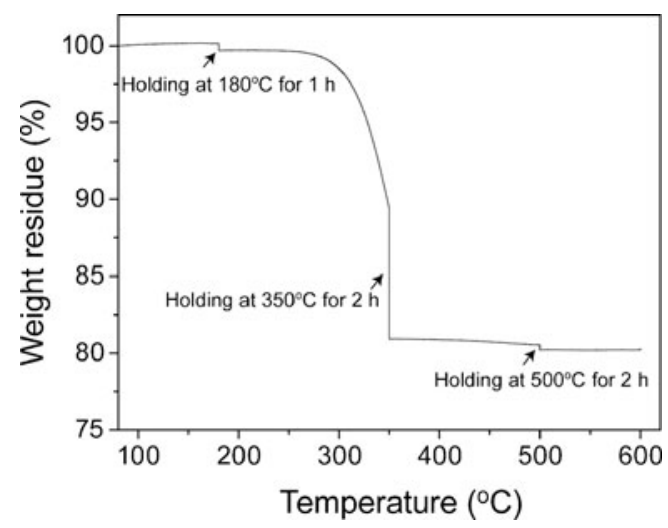

Fig. 4 Transition of weight residue of electrospun PS fibers with a gold sheath by heating. The weight of specimen at $80{ }^{\circ} \mathrm{C}$ was set as $100 \%$. Arrows show the periods at which temperatures were held for $1 \mathrm{~h}$ at $180{ }^{\circ} \mathrm{C}$ and for $2 \mathrm{~h}$ at 350 and $500{ }^{\circ} \mathrm{C}$ 
Next, we attempted to prepare gold nanoparticles in/on electrospun PS fibers as seeds of a gold sheath formation on the fibers. Incorporations of silver and gold nanoparticles in electrospun PAN fibers were reported as simple but effective ways for fabricating these metal sheaths on the fibers through electroless plating $[9,10]$. For the formation of the gold nanoparticles, we employed UV irradiation based on the report by Anka et al. [10] for in situ preparation of gold nanoparticles in electrospun PAN fibers. After the UV irradiation in this study, whitish as spun fibers (Fig. 2b) turned into purplish ones showing the existence of gold nanoparticles (Fig. 2c). In fact, gold nanoparticles of several to dozens $\mathrm{nm}$ were found by the observation of the fibers using a TEM (Fig. 2f). The diameters of the UV-irradiated fibers were not changed significantly before $(0.89 \pm$ $0.73 \mu \mathrm{m}$, Fig. $2 \mathrm{~d}$ ) and after the gold nanoparticle formation $(0.90 \pm 0.33 \mu \mathrm{m}$, Fig. 2e). A gold sheath formation was confirmed on the PS fibers containing gold nanoparticles by applying the electroless plating (Fig. 3a). The diameter of the resultant fibers with gold sheath was $1.49 \pm 0.36 \mu \mathrm{m}$. It means the formation of a gold sheath of about $300 \mathrm{~nm}$ thickness. In contrast, the gold sheath formation was not observed on the fibers without containing gold nanoparticles after applying the same electroless plating step (Fig. 3b).

Finally, we attempted to develop a hollow core structure in the PS fibers with the gold sheath. Gold hollow fibers were obtained by the heat treatment at $500{ }^{\circ} \mathrm{C}$ for $2 \mathrm{~h}$ in air (Fig. 3c). The decrease in temperature to $350{ }^{\circ} \mathrm{C}$ also resulted in the fibers with hollow structure (Fig. 3d). The hollow core structure was also induced by the heat treatment at $180{ }^{\circ} \mathrm{C}$ (Fig. 3e). It is known that PS decomposes to styrene, cumene, and ethylbenzene around $200{ }^{\circ} \mathrm{C}$ [6]. In fact, the weight of PS fibers before the treatment with the electroless plating decreased to about $35 \%$ after 2 days of standing at $180{ }^{\circ} \mathrm{C}$. An obvious difference between the hollow fibers obtained at 350 and $180{ }^{\circ} \mathrm{C}$ treatment was the double-layered structure found only for the crosssectional image of the latter specimen (Fig. 3e). It is intuitive that the inner layer is PS. This inner layer did not disappear after 3 days of treatment at $180{ }^{\circ} \mathrm{C}$ (Fig. 3f). Exact reason is not clear now but the remaining of the PS layer neighboring the gold sheath would be caused by the interaction between PS molecules and gold ions. Transition of the change in weight during heating in air (Fig. 4) supports the findings of the hollow core structure formation through heat treatments: During $1 \mathrm{~h}$ of holding at $180{ }^{\circ} \mathrm{C}$, weight of the specimen with the gold sheath decreased slightly but surely. The residual weight of the specimen decreased to $81 \%$ by the end of $2 \mathrm{~h}$ of holding at $350{ }^{\circ} \mathrm{C}$. The weight further decreased to $80 \%$ by the end of $2 \mathrm{~h}$ of holding at $500{ }^{\circ} \mathrm{C}$. No weight change was detected during the following period of heating from 500 to $600{ }^{\circ} \mathrm{C}$ and $2 \mathrm{~h}$ of holding at $600{ }^{\circ} \mathrm{C}$. These results demonstrate majority of the PS in the fibrous specimen disappeared by the heat treatment at $350{ }^{\circ} \mathrm{C}$ for $2 \mathrm{~h}$. In addition, the heat treatment at $500{ }^{\circ} \mathrm{C}$ is enough for removing the PS in the gold sheath. It was reported that gold sheathes could be formed on electrospun PAN fibers through electroless plating (but not reported on the production of gold hollow fibers) $[9,10]$. Therefore, we also investigated the possibility of using electrospun PAN fibers as a template of the hollow core structure in a gold sheath. A hollow core structure could be obtained for the PAN fiber system treated at $500{ }^{\circ} \mathrm{C}$. However, the treatment at $350{ }^{\circ} \mathrm{C}$ was not enough despite it being enough for the PS fiber system. These results demonstrate the usefulness of PS fibers as a template of gold hollow fiber preparation.

\section{Conclusion}

In this study, we aimed to develop the ultrafine gold hollow fibers. We first prepared the electrospun PS fibers containing $\mathrm{HAuCl}_{4}$ and then irradiated UV light for photoreduction resulting in the formation of gold nanoparticles in/on the PS fibers. The in situ formed gold nanoparticles were used as seeds of the subsequent gold sheath formation through electroless plating. A hollow core structure was developed by the heat treatment above $180{ }^{\circ} \mathrm{C}$. The temperature required for the decomposition of the PS fiber template was lower than that necessary for PAN fibers. From these results, we concluded that the ultrafine gold hollow fibers can be obtained in combination with electrospinning technique, photoreduction, electroless plating, and heat treatment for removing core polymer material. In addition, PS is the useful material as a fiber material on which the gold sheath forms through the electroless plating.

Acknowledgments We gratefully thank Mr. M. Kawashima, GHAS laboratory at Osaka University, for his help in the SEM measurement. In addition, we thank Prof. H. Yasuda and Dr. T. Sakata, Research Center for Ultra-High Voltage Electron Microscopy at Osaka University, for supporting the TEM measurement.

Open Access This article is distributed under the terms of the Creative Commons Attribution License which permits any use, distribution, and reproduction in any medium, provided the original author(s) and the source are credited.

\section{References}

1. Liu X, Li M, Han G, Dong J (2010) The catalysts supported on metallized electrospun polyacrylonitrile fibrous mats for methanol oxidation. Electrochim Acta 55:2983-2990

2. Huang ZM, Zhang YZ, Kotaki M, Ramakrishna S (2003) A review on polymer nanofibers by electrospinning and their applications in nanocomposites. Compos Sci Technol 63:2223-2253

3. Ramakrishna S, Fujihara K, Teo WE, Yong T, Ma ZW, Ramaseshan R (2006) Electrospun nanofibers: solving global issues. Mater Today 9:40-50 
4. Srivastava Y, Loscertales I, Marquez M, Thorsen T (2008) Electrospinning of hollow and core/sheath nanofibers using a microfluidic manifold. Microfluid Nanofluid 4:245-250

5. Marx S, Jose MV, Andersen JD, Russell AJ (2011) Electrospun gold nanofiber electrodes for biosensors. Biosens Bioelectron 26:2981-2986

6. Pfaffli P, Zitting A, Vainio H (1978) Thermal degradation products of homopolymer polystyrene in air. Scand J Work Environ Health 4(Suppl 2):22-27

7. Casper CL, Stephens JS, Tassi NG, Chase DB, Rabolt JF (2004) Controlling surface morphology of electrospun polystyrene fibers: effect of humidity and molecular weight in the electrospinning process. Macromolecules 37:573-578

8. Wannatong L, Sirivat A, Supaphol P (2004) Effects of solvents on electrospun polymeric fibers: preliminary study on polystyrene. Polym Int 53:1851-1859

9. Song X, Lei J, Li Z, Li S, Wang C (2008) Synthesis of polyacrylonitrile/Ag core-shell nanowire by an improved electroless plating method. Mater Lett 62:2681-2684

10. Anka FH, Perera SD, Ratanatawanate C, Balkus KJ (2012) Polyacrylonitrile gold nanoparticle composite electrospun fibers prepared by in situ photoreduction. Mater Lett 75:12-15 